\title{
A Note on Translations
}

VietNAMESE IS A TONAL LANGUAGE with varying regional dialects that requires the use of complex diacritic marks. Following other researchers (Luong 1992; Malarney 1996; Marr 1981, 1997; Rydstrom 2003; Zinoman 2001), I have chosen to not employ diacritic marks in order to facilitate smooth reading. In addition, as with any research involving translations, some words do not have exact translations into the English language, and some words lose their complexity once translated. When translations seriously lose intended meanings, I have provided Vietnamese translations in parentheses without diacritic marks. 

For Better or For Worse 
